\title{
Predictors of Inadequate Response to Budesonide Multimatrix in Real-World Patients with Ulcerative Colitis
}

\author{
Sydney Greenberg ${ }^{\text {a }}$ Hans H. Herfarth ${ }^{\text {b-d }}$ Edward L. Barnes ${ }^{b-d}$ \\ ${ }^{a}$ Department of Medicine, University of North Carolina at Chapel Hill, Chapel Hill, NC, USA; ${ }^{\text {b Division }}$ \\ of Gastroenterology and Hepatology, University of North Carolina at Chapel Hill, Chapel Hill, NC, USA; \\ 'Multidisciplinary Center for Inflammatory Bowel Diseases, University of North Carolina at Chapel Hill, \\ Chapel Hill, NC, USA; ${ }^{d}$ Center for Gastrointestinal Biology and Disease, University of North Carolina at Chapel Hill, \\ Chapel Hill, NC, USA
}

\section{Keywords}

Budesonide mutimatrix · Ulcerative colitis · Real-world cohort

\begin{abstract}
Background: Budesonide multimatrix (MMX) system has been approved for the induction of remission in patients with active, mild to moderate ulcerative colitis (UC), and offers potential safety benefits over more commonly utilized corticosteroid therapies. Objectives: In a real-world setting we aimed to evaluate the proportion of UC patients treated with budesonide MMX who had an inadequate clinical response, defined as requiring transition to prednisone, and to identify any predictors of inadequate response. Methods: We performed a single-center retrospective cohort study evaluating adult patients with UC, $\geq 18$ years of age, who were treated with budesonide MMX. We used bivariate and multivariable analyses to identify predictors of inadequate response to budesonide MMX. Results: Ninety-six patients were treated with budesonide MMX. Before initiation of budesonide MMX 55, 35, and 8\% were on aminosalicylate, immunomodulator, and/or biologic therapy or no therapy for UC respectively. While $54 \%$ (52/96) of patients responded to budesonide $M M X, 46 \%(44 / 96)$ required a transition to
\end{abstract}

prednisone. Patients who required transition to prednisone were more likely to be male (39 vs. $19 \%, p=0.035$ ) and younger at the time of diagnosis (median age 23.5 vs. 29.0 years, $p=0.034$ ). Age $\leq 29$ years at diagnosis (adjusted OR $3.10,95 \% \mathrm{Cl} 1.21-7.95$ ) and male sex (adjusted OR 2.96, 95\% Cl 1.12-7.77) but not concomitant therapy with biologics and/or immunomodulators or disease extent were associated with increased odds of requiring transition to prednisone. Conclusions: Budesonide MMX is effective in more than half of patients with mild-to-moderate UC. Predictors of budesonide non-response and need to transition to prednisone include male sex and younger age at diagnosis.

(c) 2019 S. Karger AG, Basel

\section{Introduction}

Budesonide multimatrix (MMX) system has been approved for the induction of remission in patients with active, mild-to-moderate ulcerative colitis (UC) [1]. Previously limited to rectal preparations, oral formulations of budesonide have been introduced in recent years. Budesonide MMX is an orally active, second-generation corticosteroid designed to deliver active drug throughout the colon.

\section{KARGER}

(c) 2019 S. Karger AG, Basel

E-Mail karger@karger.com

www.karger.com/iid
Edward L. Barnes, MD, MPH

Division of Gastroenterology and Hepatology

University of North Carolina at Chapel Hill130 Mason Farm Road

Bioinformatics Building, CB \#7080 Chapel Hill, NC 27599-7080 (USA)

E-Mail edward_barnes@med.unc.edu 
Budesonide MMX has been demonstrated in clinical trials as more effective than placebo in inducing remission in patients with active, mild-to-moderate UC [2]. When first approved as a therapy for UC, budesonide MMX offered a novel mechanism of action as it delivered budesonide throughout the colon [3], previously a limitation of prior formulations of budesonide. Budesonide MMX also offers the benefit of nearly $90 \%$ first-pass metabolism in the liver to metabolites with minimal or no corticosteroid activity [4], providing potential safety benefits over the more commonly used corticosteroid therapies such as prednisone [5], which can have significant adverse effects such as changes in blood glucose, bone metabolism, sleep disorder, and mood changes $[6,7]$. This may make budesonide MMX a desirable alternative to corticosteroids, as patients with UC identify the side effect profile and symptom relief as the most important attributes to consider when selecting a UC therapy [8]. Additionally, recent guidelines from the American College of Gastroenterology have identified several clinical scenarios where the use of budesonide MMX is appropriate if not favorable in the care of patients with UC [9].

In a pooled analysis from 2 phase 3 studies, oral budesonide MMX $9 \mathrm{mg}$ per day was associated with significant improvements in a combined clinical and endoscopic remission rate when compared to placebo [10]. Budesonide MMX has also demonstrated efficacy in patients' refractory to oral mesalamine therapy [11]. Additionally, a Cochrane review showed comparable rates of serious adverse events when comparing budesonide MMX and placebo [12]. Budesonide MMX has also been reported to be cost effective for the second-line treatment of mild to moderate UC when compared to comparators [13]. Despite these findings, in a recent network metaanalysis, budesonide MMX was not more effective than combined oral and rectal aminosalicylate therapy or high dose mesalazine, and demonstrated inferior tolerability [14].

We realize that patients treated in real-world settings are often not the same as those enrolled in clinical trials, as previously demonstrated in other tertiary care inflammatory bowel disease (IBD) clinics [15]. Additionally, in daily practice, efforts to minimize systemic steroid exposure and patient preferences drive treatment decisions [16]. To better understand the utility of budesonide MMX in patients with UC, we aimed to evaluate the real-world efficacy of budesonide MMX in the treatment of patients with active, mild-to-moderate UC in our tertiary care multidisciplinary IBD center. In this population, we aimed to evaluate the rate of inadequate clinical response, defined as requiring transition to prednisone therapy, and to identify any predictors of inadequate response.

\section{Methods}

\section{Patient Population}

We performed a retrospective cohort study, examining adult patients with mild-to-moderate UC, $\geq 18$ years of age, who were treated with budesonide MMX. All patients were treated within the University of North Carolina (UNC) Hospitals system. Patients were identified for inclusion into the study using International Classification of Diseases 9th and 10th Clinical Modification coding (556.xx and K51.xx) and the Informatics for Integrating Biology and the Bedside (i2b2) platform through the Carolina Data Warehouse for Health. The i2b2 platform was developed by the i2b2 Center, a National Institutes of Health (NIH) funded National Center for Biomedical Computing based at Partners HealthCare System in Boston, Massachusetts [17, 18]. Patients were eligible for inclusion based on the following criteria: (i) age $\geq 18$ years of age, (ii) an existing diagnosis of UC, (iii) prior treatment with budesonide MMX between January 1, 2013 and December 31, 2017 (iv) treatment in the outpatient clinic. Patients with Crohn's disease or those receiving other formulations of budesonide were excluded from these analyses.

\section{Definition of Cohorts}

Patients were grouped into 2 cohorts based on their response to budesonide MMX. Those patients requiring transition to prednisone rescue therapy were defined as having an inadequate clinical response to budesonide MMX, given the failure of budesonide MMX and need to transition to another active steroid therapy. All other patients who did not require immediate transition to prednisone were defined as responders to budesonide MMX therapy.

\section{Definition of Covariates}

Our primary aim in this study was to evaluate the rate of patients with UC treated with budesonide MMX who ultimately required transition to prednisone therapy due to inadequate response. Additionally, we aimed to identify any potential predictors of inadequate response. To identify predictors, we analyzed both demographic and clinical factors that could potentially be related to inadequate response to budesonide MMX, including age at the time of treatment, age at the time of diagnosis, sex, body mass index, race, disease extent, tobacco use, and therapy prior to the initiation of budesonide MMX and concomitant therapy at the time of budesonide. Where available, the Mayo endoscopic sub-score prior to and after treatment with budesonide MMX was also analyzed $[19,20]$.

\section{Statistical Analysis}

Continuous variables are presented using means and SDs, and compared using Student $t$ tests and Wilcoxon-rank-sum testing where appropriate. Proportions are used to express categorical variables, which were analyzed using Fisher exact and chi-square testing. Potential predictors of inadequate response to budesonide MMX (and the need for transition to prednisone) were evaluated 
using univariable and multivariable logistic regression to adjust for confounders. In multivariable logistic regression models, all variables included were selected a priori given their suspected relevance to potential response to budesonide MMX. Additionally, given our suspicion of the role that concomitant therapies may play in the efficacy of budesonide MMX, we performed secondary analyses excluding patients on concomitant biologic therapies at the time of budesonide MMX initiation. Given that this was a real-world analysis, patients with disease limited to the rectum were included in the analyses; however, a secondary analysis was performed excluding these patients. A two-tailed $p$ value of 0.05 was chosen as the threshold for statistical significance for all tests. Unadjusted and adjusted ORs and 95\% CIs are presented. All analyses were performed using SAS (version 9.4) statistical software (SAS Institute, Cary, NC, USA). The study protocol was approved by the Institutional Review Board at the UNC at Chapel Hill.

\section{Results}

A total of 96 patients with UC were treated with budesonide MMX between January 1, 2013 and December 31, 2017. Before the initiation of budesonide MMX, the majority of patients were on aminosalicylate therapy $(53 / 96 ; 55 \%)$. Of the remaining patients 18,17 , and $8 \%$ were on immunomodulator monotherapy, biologic monotherapy or combination therapy (anti-TNF [10/96] and vedolizumab [6/96]) or no UC-related therapy respectively. Of the 96 patients, $44(46 \%)$ required transition to prednisone, with 18 (19\%) requiring transition to prednisone within 4 weeks of initiation of budesonide MMX. The median age of the population was 38.0 years (interquartile range [IQR] 28-53.5), while the median duration of disease was 12.0 years (IQR 6-16) prior to initiation of budesonide MMX. The population was $28 \%$ male and $79 \%$ of patients had never smoked. When evaluating the indication for budesonide MMX, 14\% of patients initiated budesonide MMX due to prior side effects of prednisone, while $86 \%$ initiated budesonide MMX in an effort to prevent side effects of prednisone.

When comparing the baseline demographic and clinical characteristics of those patients who required transition to prednisone to those patients who responded to budesonide MMX, patients who required transition to prednisone were significantly more likely to be male (39 vs. $19 \%, p=0.035$; Table 1, Fig. 1). Patients requiring transition to prednisone were also more likely to be younger at the time of diagnosis (median age 23.5 vs. 29, $p=0.034$; Fig. 1), and were more likely to be of white race (91 vs. $77 \%, p=0.032$ across all groups). When comparing pa-

Budesonide MMX in Real-World Patients with UC tients of white race with those patients of all other racial groups, there was no significant difference noted ( $p=$ 0.067 ). There were no significant differences when comparing concomitant therapy at the time of budesonide MMX initiation.

A subset of patients had endoscopic data available prior to induction with budesonide MMX and following treatment. Among 34 patients who underwent colonoscopy prior to initiation of budesonide MMX therapy, there was no significant difference when comparing Mayo endoscopic sub-scores among patients who required transitioned to prednisone and those that did not $(p=0.511)$. Similarly, there was no difference in endoscopic outcomes among 28 patients after treatment with budesonide MMX when comparing those patients requiring transition to prednisone and those who did not, $p=0.601$ ).

Male sex was associated with increased odds of requiring transition to prednisone in both the unadjusted analysis (OR 2.64, 95\% CI 1.06-6.63) and in the multivariable analysis after adjusting for confounders (OR 2.96, 95\% CI 1.12-7.77; Table 2). Age $\leq 29$ years at diagnosis was also associated with increased odds of requiring transition to prednisone in both unadjusted (OR 2.47, 95\% CI 1.05-5.82) and adjusted (OR 3.10, 95\% CI 1.21-7.95) analyses. In a secondary analysis excluding those patients with any exposure to biologics (either prior to budesonide MMX or concomitant with initiation, $n=17$ ), male sex (adjusted OR 2.73, 95\% CI 1.04-7.17) and age $\leq 29$ years at diagnosis (adjusted OR 3.03, 95\% CI 1.19-7.71) were associated with increased odds of requiring transition to prednisone, after adjusting for disease extent. Similarly, when prior therapy utilization was added to the multivariable analysis, male sex and younger age at diagnosis remained significant predictors (online suppl. Table 1; for all online suppl. material, see www.karger.com/ doi/10.1159/000501004). Additionally, when excluding the 7 patients with disease limited to the rectum (Montreal Classification of disease extent, proctitis), there was no difference in the multivariable analysis (data not shown). When comparing response to budesonide between those patients with exposure to prednisone in the preceding 12 months and those without recent prednisone use, there was no statistically significant difference in failure of budesonide ( 40 vs. $51 \%, p=0.309$ ).

The median duration of follow-up for the entire cohort was 59 days (IQR 28-208). The median duration of budesonide MMX therapy was significantly shorter among patients who required transition to prednisone when compared to those patients who did not (43.5 vs. 83 days, $p=0.003$ ). Among the 44 patients with a lack of re- 
Table 1. Baseline demographic and clinical characteristics of patients with UC treated with budesonide MMX system

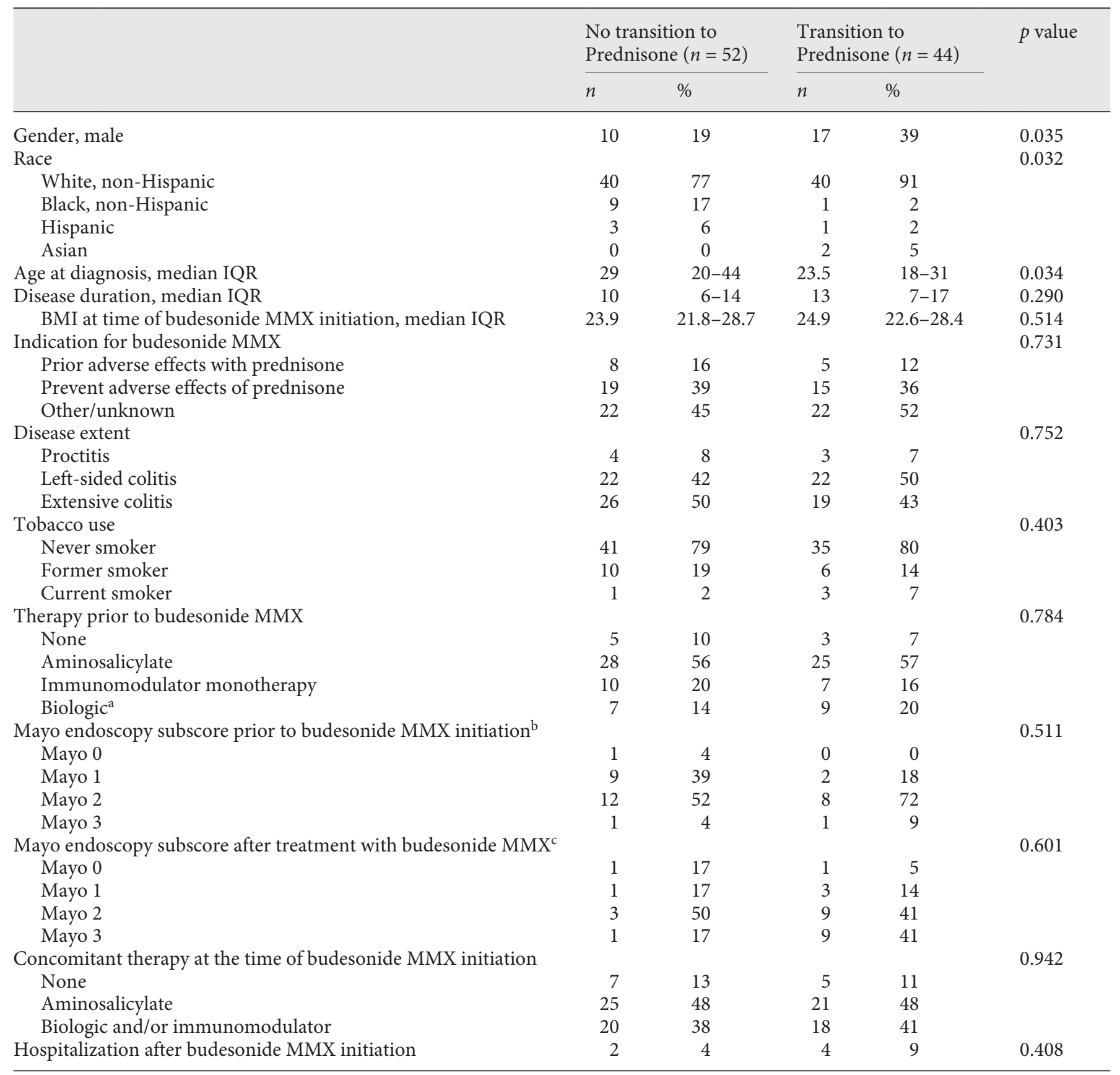

a Biologic therapy defined as monotherapy with infliximab, adalimumab, golimumab, vedolizumab or any of these agents in combination with an immunomodulator.

${ }^{\mathrm{b}}$ Mayo endoscopy subscore available for 34 patients prior to initiation (23 patients with no transition to prednisone, 11 patients with transition).

${ }^{c}$ Mayo endoscopy subscore available for 28 patients after initiation (6 patients with no transition to prednisone, 22 patients with transition).

MMX, multimatrix; IQR, interquartile range; BMI, body mass index; UC, ulcerative colitis. 
Table 2. Odds of requiring transition to prednisone therapy after budesonide MMX initiation, among patients with UC, unadjusted and adjusted analyses

\begin{tabular}{|c|c|c|}
\hline & $\begin{array}{l}\text { Unadjusted OR } \\
(95 \% \text { CI })\end{array}$ & $\begin{array}{l}\text { Adjusted OR }{ }^{\mathrm{a}} \\
(95 \% \mathrm{CI})\end{array}$ \\
\hline Gender, male & $2.64(1.06-6.63)$ & $2.96(1.12-7.77)$ \\
\hline \multicolumn{3}{|l|}{ Age at diagnosis, years } \\
\hline$\leq 29$ & $2.47(1.05-5.82)$ & $3.10(1.21-7.95)$ \\
\hline$>29$ & Reference & Reference \\
\hline \multicolumn{3}{|l|}{ Disease extent } \\
\hline Proctitis & $0.75(0.15-3.75)$ & $0.55(0.10-3.03)$ \\
\hline Left-sided colitis & Reference & Reference \\
\hline Extensive/pancolitis & $0.73(0.32-1.69)$ & $0.60(0.24-1.49)$ \\
\hline \multicolumn{3}{|c|}{ Concomitant therapy at budesonide MMX initiation } \\
\hline No therapy & $0.85(0.24-3.08)$ & $0.61(0.15-2.49)$ \\
\hline Aminosalicylate & Reference & Reference \\
\hline Biologic and/or immunomodulator & $1.07(0.45-2.54)$ & $0.88(0.35-2.25)$ \\
\hline
\end{tabular}

a All variables listed above were included in the final multivariable analysis. MMX, multimatrix; UC, ulcerative colitis.

Fig. 1. Comparison of demographic characteristics among patients who required transition to prednisone and those patients who demonstrated response to budesonide MMX system. a Comparison of median age at the time of diagnosis, ${ }^{*} p=0.034$; (b) comparison of male sex, ${ }^{* *} p=0.035$. MMX, multimatrix.

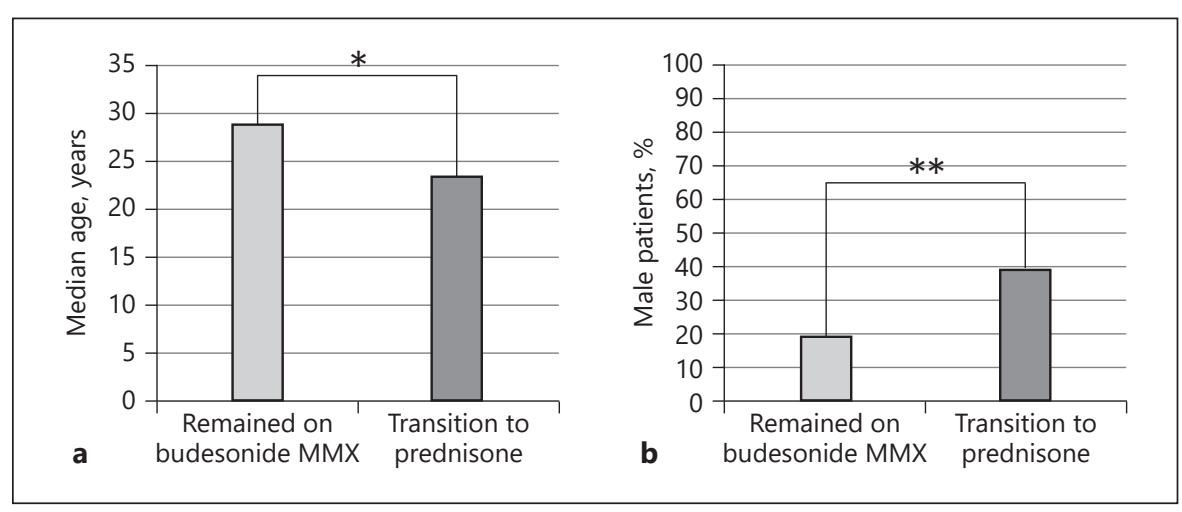

sponse to budesonide MMX, 23\% were initiated on a prednisone dose of $30 \mathrm{mg}$ daily, while $53 \%$ were initiated on a dose of $40 \mathrm{mg}$ daily. The remaining $14 \%$ were initiated on a dose of 60-75 mg daily. Of the patients who required transition to prednisone $62 \%$ achieved clinical response. When comparing those patients who subsequently responded to prednisone $(n=26)$ to those who did not $(n=16)$, patients with no treatment with prednisone in the prior 12 months were numerically more likely to respond to prednisone after a lack of response to budesonide MMX (70 vs. $33 \%, p=0.063$ ). Among those patients who did not require transition to prednisone, 5 (10\%) patients were initiated on a new anti-TNF therapy, $4(8 \%)$ were initiated on vedolizumab, and $6(12 \%)$ were initiated on a new immunomodulator therapy. There were no significant differences in therapy initiated during the study period when comparing those patients who required transition to prednisone and those who did not (online suppl. Table 2).

\section{Discussion}

In a retrospective cohort study of patients with mildto-moderate UC treated with budesonide MMX, over $45 \%$ of patients initiated on budesonide MMX therapy ultimately required transition to prednisone due to inadequate response. Following transition to prednisone, the majority of these patients achieved clinical response. In this tertiary care center population, male patients and those patients with younger age at diagnosis were more likely to require transition to prednisone when compared 
to patients who achieved adequate response to budesonide MMX. There were no differences in outcomes when evaluating UC-specific therapies prior to the initiation of budesonide MMX or when evaluating concomitant therapies at the time of budesonide MMX initiation. To our knowledge, this is the first real-world assessment of the efficacy of budesonide MMX initiated in an outpatient setting among patients with mild-to-moderate UC.

We used transition to prednisone as an indicator of inadequate clinical response to budesonide. Given the retrospective design of our study, this provided a definitive end-point for assessing the budesonide response rather than relying on the retrospective review of nonuniform provider impression. Patients were generally transitioned to prednisone because of inadequate improvement in clinical symptoms. As such, defining an inadequate response to budesonide based on an ultimate transition to prednisone provided an indirect measure of similar factors that are included in definitions of remission in other studies of budesonide for UC $[10,11]$. In our study, $54 \%$ of patients did not require transition to prednisone, suggesting an adequate response to budesonide. While this is a notably higher rate of response when compared to a meta-analysis of 3 studies showing a remission rate of $15 \%$ in patients treated with budesonide MMX [12], these trials used a stringent definition of remission that required both adequate clinical and endoscopic responses. Requiring both clinical and endoscopic response rather than either finding alone may account for the difference in findings.

UC poses a significant burden to health care resources. Studies have estimated that the direct medical costs of UC were USD 2.7 billion [21], with health insurer and patient out-of pocket expenditures between USD 390 and 920 million [22]. With the incidence of UC increasing and the highest incidence of diagnosis occurring in the second to fourth generations of life [23], this disease may continue to have substantial economic impact. Budesonide MMX has also been reported to be cost effective for the secondline treatment of mild to moderate UC when compared to comparators [13]. Given the growing potential impact of UC on the healthcare system, it is prudent to identify predictive factors of budesonide MMX efficacy to further determine its place within treatment paradigms for US.

When assessing factors that may predict inadequate response to budesonide, there was a statistically significant association between male sex and transition to prednisone. This is in contrast to the findings of a pooledanalysis of 2 phase- 3 studies that males and females had comparable rates or remission (17.7 and $17.6 \%$, respec- tively) [10]. Following transition to prednisone there was no significant difference in clinical response when comparing male and female patients (data not shown). One potential explanation for these findings is a difference in compliance with UC therapies that has been demonstrated between male and female patients [24]. Given the association of prednisone with weight gain, facial hair, and other systemic effects $[25,26]$, female patients may have also preferred continued therapy with budesonide as opposed to transition to prednisone; however, we could not explore these potential explanations further.

We also demonstrated a statistically significant increase in the odds of requiring transition to prednisone among patients with a younger age at diagnosis. This may indicate a more aggressive presentation [27] or potentially an increased risk for complications [28]. Although more patients of white race required transition to prednisone after induction with budesonide MMX, the population of non-white patients was underpowered to further evaluate these differences. Additionally, although a prior Cochrane review has suggested that left-sided disease is possibly a predictor of response to budesonide MMX [12], we did not demonstrate a significant association between disease extent and a need for transition to prednisone. Given the associations demonstrated in our population, these factors may require consideration by physicians when prescribing in the future.

We did not detect a negative association for budesonide MMX response and the concomitant use of biologics. The most recent guidelines for the treatment of patients with UC reference the positioning of budesonide MMX among patients with mild or moderate UC $[9,29]$; however, in $18 \%$ of patients in this real-world cohort, budesonide MMX was initiated in patients with prior or concomitant biologic exposure. When patients with concomitant use of biologics were excluded from the multivariable analyses, the response patterns to budesonide MMX were similar to those of the overall population. Although the use of budesonide MMX among patients concomitantly treated with biologics is somewhat higher than we might have anticipated, this is a real-world cohort of patients with UC, and is reflective of how budesonide MMX is being utilized in clinical practice for the treatment of patients with UC.

Determining the role of budesonide within treatment paradigms for UC is an evolving discussion [14, 30]. There was no significant association between previous or current therapies and transition to prednisone, including patients on prior biologics or who previously required prednisone. Our findings are consistent with studies that 
have demonstrated the efficacy of budesonide for mesalamine-refractory UC [10]. Additionally, there was no significant difference the initiation of new therapies, including biologic therapies, when comparing patients who remained on budesonide MMX and those requiring transition to prednisone.

Our study had multiple strengths, including the use of a hard outcome of transition to prednisone to define inadequate response to budesonide MMX in an effort to avoid assessing more subjective definitions of clinical response retrospectively. However, our study does have limitations. Despite defining a transition to prednisone as our primary outcome, our study remains a retrospective analysis of the efficacy of budesonide MMX. In those patients requiring transition to prednisone, the dosage of prednisone after transition was not uniform. Although the medication patterns prior to and concomitant with budesonide MMX induction were not predictive of response to budesonide MMX, this was a tertiary care multidisciplinary IBD center population. Additionally, although multiple significant predictors of inadequate response to budesonide MMX were identified, this remains a relatively small population limiting the number of predictors that could be included in the final multivariable models. Disease assessment by endoscopy prior to the initiation of budesonide was available in a minority of patients, which may reflect the choice to use budesonide MMX in a population of patients with a disease course that was predicted to be relatively mild at the time of initiation.

In conclusion, in a retrospective analysis of patients with mild to moderate UC treated as outpatients at a tertiary care referral IBD center, over $45 \%$ of patients treated with budesonide MMX required transition to prednisone therapy. Although budesonide MMX is effective for more than half of the patients with mild-to- moderate UC, potential limitations of efficacy may be considered among certain populations including male patients and those with earlier disease onset. Continued evaluation of the appropriate position of budesonide MMX will be critical, even in populations with potential for decreased response to therapy. Given that prednisone is an effective therapy after inadequate response to budesonide MMX in the majority of patients, and that the overall response rates to budesonide MMX compare favorably to those reported in clinical trials, a short trial of budesonide MMX may still be warranted even in these populations.

\section{Acknowledgements}

$\mathrm{i} 2 \mathrm{~b} 2$ software was used in conducting this study. i2b2 is the flagship tool developed by the i2b2 (Informatics for Integrating Biology and the Bedside) Center, an NIH funded National Center for Biomedical Computing based at Partners HealthCare System. The i2b2 instance at the UNC is supported by the National Center for Advancing Translational Sciences, NIH, through Grant Award Number UL1TR002489. The content is solely the responsibility of the authors and does not necessarily represent the official views of the NIH.

\section{Disclosure Statement}

S.G. has no relevant disclosures. H.H.H. received consulting fees from Alivio, AMAG, Finch, Merck, Pfizer, Celltrion, Lycera, Boehringer-Ingelheim, and Seres and research support from Artizan and Pfizer. E.L.B. has received consulting fees from Janssen Biotech, Inc. and Abbvie, Inc.

\section{Funding Sources}

E.L.B. is supported by a Career Development Award from the Crohn's and Colitis Foundation (award number 567497). This project was also supported in part by the Center for Gastrointestinal Biology and Disease, NIH (P30DK07634).

\section{References}

1 Abdalla MI, Herfarth $\mathrm{H}$. Budesonide for the treatment of ulcerative colitis. Expert Opin Pharmacother. 2016 Aug;17(11):1549-59.

2 Sandborn WJ, Travis S, Moro L, Jones R, Gautille T, Bagin R, et al. Once-daily budesonide $\mathrm{MMX}^{\circledR}$ extended-release tablets induce remission in patients with mild to moderate ulcerative colitis: results from the CORE I study. Gastroenterology. 2012 Nov; 143(5):1218-26.e2.

3 Danese S, Siegel CA, Peyrin-Biroulet L. Review article: integrating budesonide-MMX into treatment algorithms for mild-to-moderate ulcerative colitis. Aliment Pharmacol Ther. 2014 May;39(10):1095-103.

4 Ryrfeldt A, Andersson P, Edsbäcker S, Tönnesson M, Davies D, Pauwels R. Pharmacokinetics and metabolism of budesonide, a selective glucocorticoid. Eur J Respir Dis Suppl. 1982;122:86-95.

5 D'Haens G. Systematic review: second-generation vs. conventional corticosteroids for induction of remission in ulcerative colitis. Aliment Pharmacol Ther. 2016 Nov;44(10):1018-29.
6 Bonovas S, Nikolopoulos GK, Lytras T, Fiorino G, Peyrin-Biroulet L, Danese S. Comparative safety of systemic and low-bioavailability steroids in inflammatory bowel disease: systematic review and network meta-analysis. $\mathrm{Br}$ J Clin Pharmacol. 2018 Feb;84(2):239-51.

7 Kornbluth A, Sachar DB; Practice Parameters Committee of the American College of Gastroenterology. Ulcerative colitis practice guidelines in adults: American College Of Gastroenterology, Practice Parameters Committee. Am J Gastroenterol. 2010 Mar;105(3):501-23. 
8 Gray JR, Leung E, Scales J. Treatment of ulcerative colitis from the patient's perspective: a survey of preferences and satisfaction with therapy. Aliment Pharmacol Ther. 2009 May; 29(10):1114-20.

9 Rubin DT, Ananthakrishnan AN, Siegel CA, Sauer BG, Long MD. ACG Clinical Guideline: Ulcerative Colitis in Adults. Am J Gastroenterol. 2019 Mar;114(3):384-413.

10 Sandborn WJ, Danese S, D’Haens G, Moro L, Jones R, Bagin R, et al. Induction of clinical and colonoscopic remission of mild-to-moderate ulcerative colitis with budesonide MMX $9 \mathrm{mg}$ : pooled analysis of two phase 3 studies. Aliment Pharmacol Ther. 2015 Mar;41(5) $409-18$.

11 Rubin DT, Cohen RD, Sandborn WJ, Lichtenstein GR, Axler J, Riddell $\mathrm{RH}$, et al. Budesonide Multimatrix Is Efficacious for Mesalamine-refractory, Mild to Moderate Ulcerative Colitis: A Randomised, Placebo-controlled Trial. J Crohn's Colitis. 2017 Jul;11(7): 785-91.

12 Sherlock ME, MacDonald JK, Griffiths AM, Steinhart AH, Seow $\mathrm{CH}$. Oral budesonide for induction of remission in ulcerative colitis. Cochrane Database Syst Rev. 2015 Oct;(10): CD007698.

13 Gherardi A, Roze S, Kuijvenhoven J, Ghatnekar O, Yip Sonderegger YL. Budesonide with multi-matrix technology as second-line treatment for ulcerative colitis: evaluation of long-term cost-effectiveness in the Netherlands. J Med Econ. 2018 Sep;21(9):869-77.

14 Nguyen NH, Fumery M, Dulai PS, Prokop LJ, Sandborn WJ, Murad MH, et al. Comparative efficacy and tolerability of pharmacological agents for management of mild to moderate ulcerative colitis: a systematic review and network meta-analyses. Lancet Gastroenterol Hepatol. 2018 Nov;3(11):742-53.

15 Ha C, Ullman TA, Siegel CA, Kornbluth A. Patients enrolled in randomized controlled trials do not represent the inflammatory bow- el disease patient population. Clin Gastroenterol Hepatol. 2012 Sep;10(9):1002-7; quiz e78.

16 Siegel CA. Shared decision making in inflammatory bowel disease: helping patients understand the tradeoffs between treatment options. Gut. 2012 Mar;61(3):459-65.

17 Murphy S, Wilcox A. Mission and Sustainability of Informatics for Integrating Biology and the Bedside (i2b2). EGEMS (Wash DC). 2014 Sep;2(2):1074.

18 Murphy SN, Weber G, Mendis M, Gainer V, Chueh HC, Churchill S, et al. Serving the enterprise and beyond with informatics for integrating biology and the bedside (i2b2). J Am Med Inform Assoc. 2010 Mar-Apr;17(2): 124-30.

19 Schroeder KW, Tremaine WJ, Ilstrup DM. Coated oral 5-aminosalicylic acid therapy for mildly to moderately active ulcerative colitis. A randomized study. N Engl J Med. 1987 Dec; 317(26):1625-9.

20 D'Haens G, Sandborn WJ, Feagan BG, Geboes K, Hanauer SB, Irvine EJ, et al. A review of activity indices and efficacy end points for clinical trials of medical therapy in adults with ulcerative colitis. Gastroenterology. 2007 Feb; 132(2):763-86.

21 Molodecky NA, Soon IS, Rabi DM, Ghali WA, Ferris M, Chernoff G, et al. Increasing incidence and prevalence of the inflammatory bowel diseases with time, based on systematic review. Gastroenterology. 2012 Jan;142(1): 46-54.e42; quiz e30.

22 Kappelman MD, Rifas-Shiman SL, Porter CQ, Ollendorf DA, Sandler RS, Galanko JA, et al. Direct health care costs of Crohn's disease and ulcerative colitis in US children and adults. Gastroenterology. 2008 Dec;135(6): 1907-13.

23 Gunnarsson C, Chen J, Rizzo JA, Ladapo JA, Lofland JH. Direct health care insurer and out-of-pocket expenditures of inflammatory bowel disease: evidence from a US national survey. Dig Dis Sci. 2012 Dec;57(12):308091.

24 Kane SV, Cohen RD, Aikens JE, Hanauer SB. Prevalence of nonadherence with maintenance mesalamine in quiescent ulcerative colitis. Am J Gastroenterol. 2001 Oct;96(10): 2929-33

25 Andus T, Gross V, Caesar I, Schulz HJ, Lochs $\mathrm{H}$, Strohm WD, et al.; German/Austrian Budesonide Study Group. Replacement of conventional glucocorticoids by oral $\mathrm{pH}$ modified release budesonide in active and inactive Crohn's disease: results of an open, prospective, multicenter trial. Dig Dis Sci. 2003 Feb;48(2):373-8.

26 Cortot A, Colombel JF, Rutgeerts P, Lauritsen K, Malchow H, Hämling J, et al.; Van Gossum A. Switch from systemic steroids to budesonide in steroid dependent patients with inactive Crohn's disease. Gut. 2001 Feb; 48(2):186-90.

27 Charpentier C, Salleron J, Savoye G, Fumery M, Merle V, Laberenne JE, et al. Natural history of elderly-onset inflammatory bowel disease: a population-based cohort study. Gut. 2014 Mar;63(3):423-32.

28 Herzog D, Fournier N, Buehr P, Rueger V, Koller R, Heyland K, et al.; Swiss IBD Cohort Study Group. Age at disease onset of inflammatory bowel disease is associated with later extraintestinal manifestations and complications. Eur J Gastroenterol Hepatol. 2018 Jun; 30(6):598-607.

29 Ko CW, Singh S, Feuerstein JD, Falck-Ytter C, Falck-Ytter Y, Cross RK, et al.; American Gastroenterological Association Institute Clinical Guidelines Committee. AGA Clinical Practice Guidelines on the Management of Mildto-Moderate Ulcerative Colitis. Gastroenterology. 2019 Feb;156(3):748-64.

30 Lichtenstein GR. Budesonide Multi-matrix for the Treatment of Patients with Ulcerative Colitis. Dig Dis Sci. 2016 Feb;61(2): $358-70$. 